\title{
El signo de la cáscara de manzana en vólvulo de intestino medio
}

\section{Drs. Michael Hirsch $S^{(1)}$, Claudio Cortés $A^{(2)}$.}

1. Residente de Radiología, Centro de Imagenología, Hospital Clínico Universidad de Chile. Santiago, Chile.

2. Radiólogo, Profesor Asociado Facultad de Medicina, Universidad de Chile. Centro de Imagenología, Hospital Clínico Universidad de Chile. Santiago, Chile.

\section{The apple-peel syndrome in midgut volvulus}

Abstract: The apple-peel sign represents an image visualized on oral contrast-enhanced examination of the upper gastrointestinal tract in patients with midgut volvulus. Its recognition is vital for a timely diagnosis to prevent treatment delay, since this condition represents a true surgical emergency.

Key word: Abdominal radiography, Midgut, Radiology, Volvulus.

Resumen: El signo de la cáscara de manzana corresponde a una imagen visualizada en el estudio con contraste oral del tubo digestivo alto en pacientes que presentan vólvulo del intestino medio. Su reconocimiento es fundamental para hacer el diagnostico de manera oportuna, sin retrasar el tratamiento, ya que se considera una emergencia quirúrgica.

Palabras clave: Intestino medio, Radiología, Radiografía abdominal, Vólvulo.

Hirsch M. El signo de la cáscara de manzana en vólvulo de intestino medio. Rev Chil Radiol 2011; 17(2): 90-92. Correspondencia: Dr. Michael Hirsch S. / mphirsch@gmail.com

Trabajo recibido el 26 de octubre de 2010, aceptado para publicación el 12 de abril de 2011.

\section{Aspecto imaginológico}

El signo de la cáscara de manzana (Apple-peel sign) que presentamos, corresponde a la visualización, en un estudio con medio de contraste vía oral, de una imagen espiral, que corresponde a la cuarta porción del duodeno y yeyuno proximal volvulado sobre el eje mesentérico, habitualmente en un paciente con malrotación intestinal. Este signo recibe otros nombres como el signo del "sacacorchos" o signo del "espiral"(1).

\section{Reseña histórica}

El primer autor que utilizó el término "cáscara de manzana" fue Santulli et al. en $1961^{(2)}$, refiriéndose al aspecto de un tipo de atresia duodenal o yeyunal alta, asociada a ausencia de mesenterio del intestino delgado y de las arcadas arteriales de la arteria mesentérica superior. La apariencia que resulta del intestino delgado distal, alejándose del ciego y torciéndose libremente sobre la arteria marginal que lo nutre, sugieren el aspecto de una cáscara de manzana (Figura 1) ${ }^{(3,4)}$. Este término es aplicado a otras volvulaciones del intestino, en particular al del intestino medio en la malrotación intestinal.

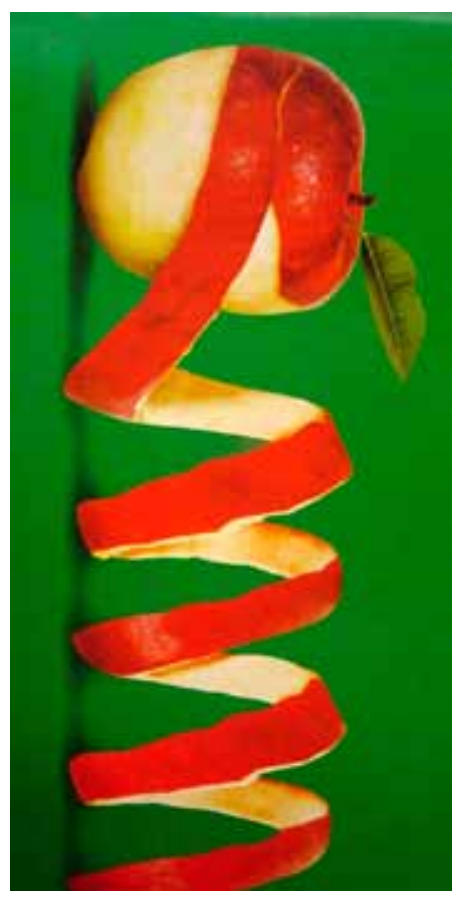

Figura 1. Imagen de cáscara de manzana a la que se hace referencia en el signo imaginológico. 


\section{Significado}

En el período fetal, el tracto gastrointestinal se desarrolla a partir de una formación tubular recta y corta. Algunos autores clasificaron el intestino medio primitivo en dos partes, usando como referencia la arteria mesentérica superior (AMS). La primera parte consiste en las asas proximales preareterial duodeno-yeyunales e ílion proximal, que se encuentran por delante y por encima de la AMS. La segunda parte incluye las asas distales postarterial que se encuentra por debajo y detrás de la AMS, e incluye el íleon distal, colon derecho y los dos tercios proximales del colon transverso. A medida que el intestino se alarga, los segmentos prearterial y postarterial rotan en una dirección antihoraria alrededor de la AMS, fijándose posteriormente el mesenterio que sostiene estas asas a la pared abdominal posterior ${ }^{(5)}$. Producto de esta rotación, en una persona normal, el mesenterio del intestino delgado se localiza desde el ángulo de Treitz, en el cuadrante superior izquierdo del abdomen, descendiendo, cruzando la línea media, hasta llegar a la unión ileocecal en el cuadrante inferior derecho. Por su parte el duodeno, dividido clásicamente en cuatro porciones, tiene un recorrido hacia posterior (1ra porción), luego inferior (2da porción), posteriormente anterior y horizontal de derecha a izquierda, cruzando la línea media (3ra porción) y finalmente una porción que sigue una dirección ascendente y posterior (4ta porción) hasta llegar a la flexura duodeno-yeyunal (ángulo de Treitz) ${ }^{(6)}$. En el caso de una malrotación intestinal, la rotación antihoraria que se produce en el período fetal, alrededor de la AMS, se ve alterada, en forma parcial o total. En este caso la 3ra y 4ta porción del duodeno, además del yeyuno, siguen una dirección caudal, sin cruzar la línea media, con un ángulo de Treitz a derecha y en una posición inferior. Esta condición reduce el área de implantación del mesenterio, facilitando la rotación de éste sobre su propio eje, promoviendo así la volvulación del intestino medio. Este vólvulo es el que genera el signo de la cáscara de manzana (Figuras 2 y 3 ).

Al rotar el intestino medio sobre su mesenterio, se afecta en primera instancia el drenaje venoso del intestino, lo que provoca edema de las asas. Posteriormente se compromete la irrigación arterial, que por tener una mayor presión resiste más tiempo a la torsión. Estos fenómenos, en conjunto con la obstrucción intestinal en asa cerrada que se genera, promueven el daño en la mucosa y la permeación bacteriana, lo que puede llevar a un Síndrome de Respuesta Inflamatoria Sistémica, con sepsis severa y finalmente la muerte.

Como signo asociado a la cáscara de manzana se puede apreciar dilatación del duodeno producto de la obstrucción.
Es esperable que se comprometa todo el intestino delgado a excepción de las primeras porciones del duodeno(1).

Por lo general, el cuadro se presenta en las primeras semanas de vida, aunque se han publicado casos en adultos ${ }^{(7)}$ y son característicos los vómitos biliosos.

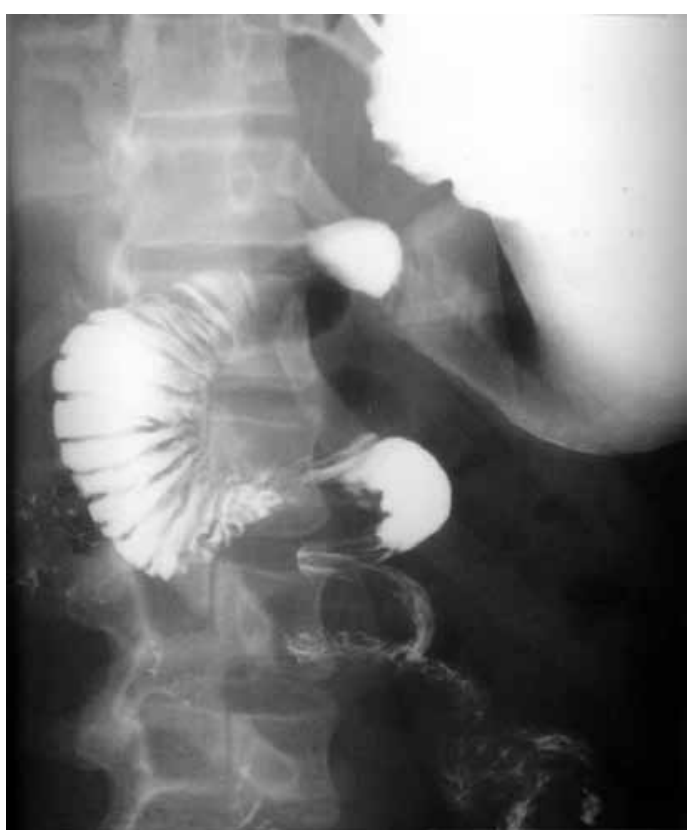

Figura 2. Estudio digestivo con contraste baritado vía oral en que se demuestra una volvulación de intestino medio con el signo de la cáscara de manzana.

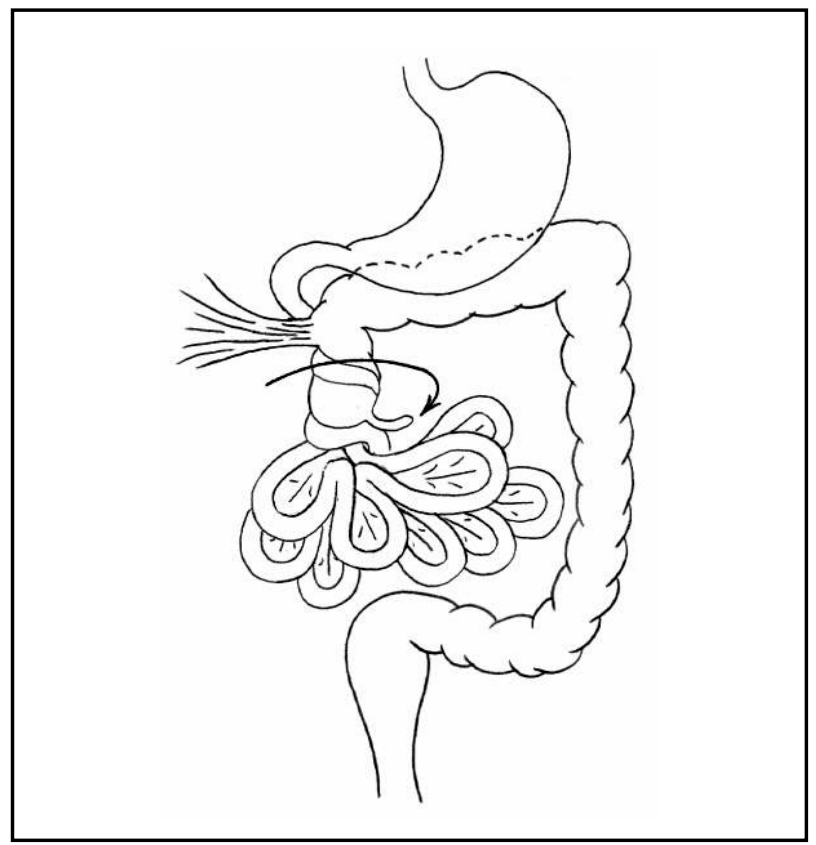

Figura 3. Dibujo que grafíca el vólvulo de intestino medio en un cuadro de malrotación intestinal. La rotación del intestino sobre el eje mesentérico genera el signo de la cáscara de manzana. 


\section{Diagnóstico diferencial}

No hemos encontrado estudios publicados que demuestren sensibilidad ni especificidad de este signo, como tampoco diagnósticos diferenciales, por lo que su presencia hace muy sugerente el diagnóstico de vólvulo de intestino medio(8).

\section{Discusión}

El signo de la cáscara de manzana o sacacorchos es un indicador de vólvulo de intestino medio en el estudio radiológico con contraste oral. Esta condición es habitual en pacientes con malrotación intestinal y se considera una emergencia quirúrgica debido al amplio compromiso del intestino delgado, en que se produce alteración del drenaje venoso, irrigación arterial, obstrucción en asa cerrada y en última instancia permeación de la flora bacteriana y compromiso vital del paciente. Por esta razón es importante saber reconocer este signo y evitar así el manejo tardío, ya que de la oportuna intervención depende la sobrevida y morbilidad de quien sufre esta condición.

\section{Bibliografía}

1. Ortiz-Neira C. The Corkscrew Sign: Midgut Volvulus. Radiology 2007; 242: 315-316.

2. Santulli TV, Blanc WA. Congenital atresia of the intestine. Pathogenesis and treatment. Ann Surg 1961; 154: 939-948.

3. Blyth H, Dickson JA. Apple peel syndrome (congenital intestinal atresia): a family study of seven index patients. J Med Genet 1969; 6(3): 275-277.

4. Leonidas JC, Amoury RA, Ashcraft KW, Fellows RA. Duodenojejunal atresia with "apple-peel" small bowel. A distinct form of intestinal atresia. Radiology 1976; 118(3): 661-665.

5. Snyder WH, Chaffin L. Embriology and pathology of the intestinal tract: presentation of 40 cases of malrotation. Ann Surg 1954; 140: 368-380.

6. Dott NM. Anomalies of intestinal rotation: their embryology and surgical aspects: with report of five cases. Br J Surg 1923; 192: 251-286.

7. Hsu SD, Yu JC, Chou SJ, Hsieh HF, Chang TH, Liu YC. Midgut volvulus in an adult with congenital malrotation. Am J Surg 2008; 195(5): 705-707.

8. Long FR, Kramer SS, Markowitz RI, Taylor GE. Radiographic patterns of intestinal malrotation in children. Radiographics 1996; 16(3): 547-556.

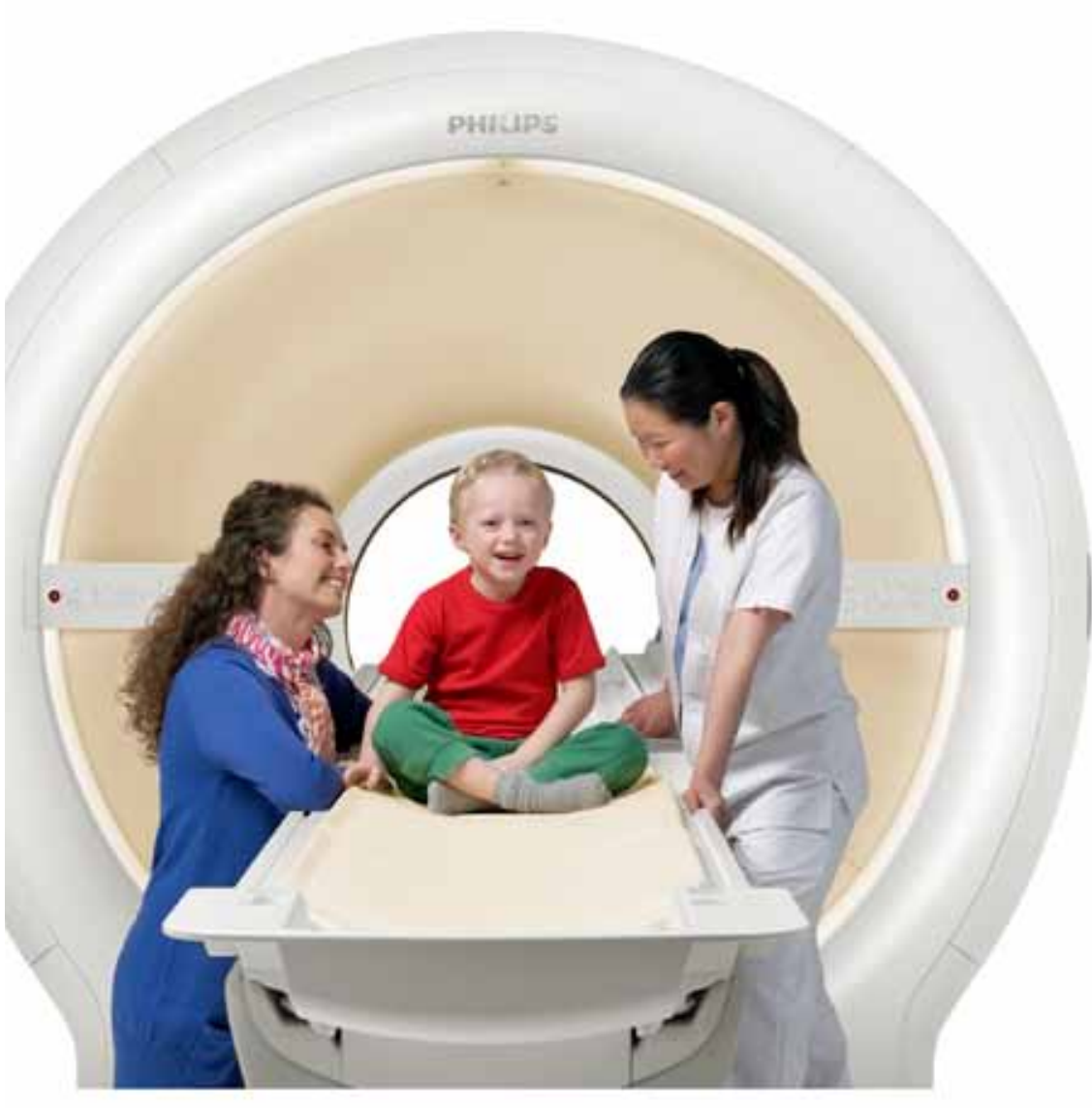

\section{Imaging}

Al igual que la web 2.0 redefinió la forr que las personas se conectan, compa| usan internet, Imaging 2.0 represen nuevo mundo de posibilidades para la । logía. Se refiere a integración, colabor: nuevos niveles de enfoque de paciente guridad que ayudarán al especialista canzar lo que era inimaginable hace pocos años atrás. 